\title{
Magnetic Measurements on the Magnets Used in the New Low- $\beta$ Insertions at BO and D0
}

\author{
Norman M. Gelfand \\ Fermi National Accelerator Laboratory \\ P.O. Box 500, Batavia, Illinois 60510
}

\section{DISCLAIMER}

This report was prepared as an account of work sponsored by an agency of tie United States Government. Neither the United States Government nor any agency thereof, nor any of their employees, makes any warranty, express or implied, or assumes any legal liability or responsibility for the accuracy, completeness, or usefulness of any information, apparatus, product, or process disclosed, or represents that its use would not infringe privately owned rights. Reference herein to any specific commercial product, process, or service by trade name, trademark, manufacturer, or otherwise does not necessarily constitute or imply its endorsement, recommendation, or favoring by the United States Government or any agency thereof. The views and opinions of authors expressed herein do not necessarily state or reflect those of the United States Government or any agency thereof.

May 1993 


\section{Disclaimer}

This report was prepared as an account of work sponsored by an agency of the United States Government. Neither the United States Government nor any agency thereof, nor any of their employees, makes any warranty, express or implied, or assumes any legal liability or responsibility for the accuracy, completeness, or usefulness of any information, apparatus, product, or process disclosed, or represents that its use would not infringe privately owned rights. Reference herein to any specific commercial product, process, or service by trade name, trademark, manufacturer, or otherwise, does not necessarily constitute or imply its endorsement, recommendation, or favoring by the United States Government or any agency thereof. The views and opinions of authors expressed herein do not necessarily state or reflect those of the United States Government or any agency thereof. 


\title{
Magnetic Measurements on the Magnets Used in the New Low- $\beta$ Insertions at $\mathrm{B} 0$ and $\mathrm{D} 0$
}

\author{
Norman M. Gelfand*
}

April 23, 1993

This report is a compilation of the data obtained from the MTF measurements made of the superconducting low- $\beta$ quadrupole magnets and spools used in the low- $\beta$ inserts at B0 and D0 in the Tevatron. The measurements were done at $4.6 \mathrm{~K} .{ }^{1}$ Very high gradients are required in these quadrupoles needed to achieve a value of the amplitude function $\beta$, of $0.25 \mathrm{~m}$ at the interaction point. The transfer function, viz. the gradient for a given current in the coils has a nominal value of $0.2913 \mathrm{~T} / \mathrm{cm} / \mathrm{kA}$ in the two shell quadrupoles and $0.5825 \mathrm{~T} / \mathrm{cm} / \mathrm{kA}$ in the one shell quadrupole built from segmented 5 -in-1 conductor. ${ }^{2}$ As a comparison the transfer constants in the superconducting lattice quads in the Tevatron have a transfer constant of $\approx 0.173 \mathrm{~T} / \mathrm{cm} / \mathrm{kA}$. This improvement in performance is the result of the $R \& D$ effort, at Fermilab, that preceeded the construction of these magnets.

In those cases where the data are not presented in the same way as they are reported by MTF, I will explain the method by which the data have been reduced to produce the numbers in this report.

Not all the available data are reproduced in this report. They are stored in one or more data bases and can be retrieved when needed.

\footnotetext{
-Work supported by the U.S. Department of Energy under contract No. DE-AC02$76 \mathrm{CHO} 000$.

${ }^{1}$ A discussion of the measurement procedure and techniques at MTF are beyond the scope of this report.

2nTevatron Low Beta Quadrupoles. Requirements and Specifications." (The "Pink Book") Feb. 15, 1990.
} 


\section{Low- $\beta$ Quadrupoles}

The low- $\beta$ quadrupoles include the 132" quadrupoles in the triplet ( 22 and Q4), the 232" quadrupoles in the triplet (Q3) and the 54" quadrupoles (Q1 and Q5). The following magnetic measurements (among others) have been performed at MTF:

- The quench current. The quench current is the maximum current in the magnet before the magnet quenches.

- The high order multipoles. The magnetic field in the quadrupoles is measured, as a function of excitation current, and expressed in terms of harmonic coefficients of the coordinates of the transverse position in the magnet.

- Integrated gradient. The $\int B^{\prime} d l$ has been measured, as a function of current, with a stretched wire system.

\section{Quench Current}

The quench current has been measured for the low- $\beta$ quadrupoles. In addition, for most of the magnets, "endurance" and "cycle" tests were performed in order to test the magnets under conditions that more closely approximate the conditions at which they will be operated in the TEVATRON. Table I gives the results of the MTF tests.

The needed quench current for the long (132" and 232") quadrupoles is $4800 \mathrm{amps}$ at $1 \mathrm{Tev}$. For the 54" quadrupoles the required quench current is 2900 amps. Thus all the low- $\beta$ quadrupoles meet the requirements for a $0.25 \mathrm{~m} \beta^{*}$ and $1 \mathrm{TeV}$ operation.

\section{Harmonics}

The magnetic field in the magnets was measured with a rotating coil, and from these measurements, the harmonic coefficients can be extracted. The measurements were made at different currents while the current was increasing and also when the current was decreasing. Thus both the hysteresis and the current dependence of the moments for each of the magnets can be calculated from the measurements. The results of the calculation are not presented here but they are stored in a data base. Figure 1 is a plot of the 
average and the variance ${ }^{3}$ for the harmonics, at the maxioum current at which they were measured, for the different multipole coefficients and for the different types of low- $\beta$ magnets. The averages of $b_{n}$ and $a_{n}$ are, except for the allowed moments $b_{5}, b_{9}$, and $b_{13}$, small and are less than $10^{-4} / \mathrm{in}^{n}$. The data are summarized in Table II.

\section{Transfer Constants.}

The transfer constant of a quadrupole is the gradient (expressed in $\mathrm{T} / \mathrm{cm}$ ) per $\mathrm{kA}$ in the coils. It is not measured directly but rather the integrated gradient, i.e. $\int B^{\prime} a^{\prime} l$, was measured for the low- $\beta$ quadrupoles. The rneasurements were performed using a stretched wire array constructed from tungsten wire. It is expected that the value of the transfer constant will be dependent on the current, due to persistent current effects at small values of the current and to the onset of iron saturation at large values. Because of this the measurements of $\int B^{\prime} d l$ are made at a large number of currents. Measurements are made with the current increasing and were repeated many times and the final results are an average of all of the measurements made at a particular current.

Problems nave been idenified, both with the technique, i.e. the use of tungsten wires, and also with the calibration of the current monit iss. There has not been, to my knowledge, a ccmparison of the current monitors at MTF with those used in the Tevatron. Therefore caution must be exercised when using the reported values of the transfer constants to compute the currents needed to obtain the desired gradients in tile Tevatron. Any difference, or error in the calibrations in the current monitors, will result in the need to apply a uniform scale factor to all the transfer constants, it will not affect the relative strength of the quadrupoles. The values originally distributed, referred to in this note as the uncorrected values have recently been su perceded, for the 132" and the 232" quadrupoles, by a set of values corrected for the paramagnetism of the tungsten wire. These new values are referred $t 0$ as the corrected values. ${ }^{4}$ Since the error for the shorter 54 " magnets is tho wh 1 to be small no corrected values have been calculated and distributed.

The transfer constant is calculated from the measured $\int B^{\prime} d l, f r r$ a given current, and by dividing by the length of the magnet and the value of the

\footnotetext{
${ }^{3}$ The variance is the r.m.s difference between the individual measurements and the mean of the measurements

${ }^{4}$ These corrected values also include a correction for the remnant field.
} 
current at which the measurement was made. Table III gives the values of the magnet lengths used to compute the transfer constants. ${ }^{2}$

Figure 2 shows the uncorrected variation, with current, of the transfer constant for each of the low- $\beta$ quadrupoles. ${ }^{5}$ For the shorter quadrupoles the 54 " and 132 " magnets, the transfer constant appears to change by $\approx 0.5 \%$ over the range of currents used in the measuremenus. For the 232" magnets the change is $\approx 1.0 \%$. At least part of the apparent current dependence, the rise in the transfer constant at high currents is believed due to the paramagnetic behavior of the tungsten wire. The error made by neglecting the paramagnetic nature of tungsten depends on the length of the quadrupole. Figure 3 show both the uncorrected and the corrected transfer constants for the 132" and 232" quadrupoles. "Both sets of values are summarized in Table IV.

Table $\mathrm{V}$ and figure 4 give the average of the data, at a given current, for the 132" and the 232" quadrupoles. If we accept these data at face value we would conclude that the transfer constant for the 232" quadrupoles is larger than transfer constant of the 132 " quadrupoles by $\approx 0.00032 \mathrm{~T} / \mathrm{cm} / \mathrm{kA}$ corresponding to a difference in strength of $\approx 0.1 \%$.

Even the corrected values of the transfer constants for the 132" and 232" quadrupoles, have a magnet to magnet variation in the transfer constant of about $\mathbf{0 . 5 \%}$. It is necessary to ask if this variation is due to the precision of the measurements or to a real variation in the transfer constant, presumably due to a variation in the magnet length of the magnets. ${ }^{7}$

In order to answer this question we make the reasonable assumption that the measurement error is independent of the length of the magnet and that there is a fixed uncertainty in the length of the magnet. In that case the fractional uncertainty in the strength of a quadrupole will be:

$$
\delta_{t}^{2}=\delta_{m}^{2}+\left(\delta_{l} / l\right)^{2}
$$

where:

$\delta_{t}$ The fractional uncertainty in the measured transfer constant.

\footnotetext{
${ }^{8}$ Unfortunately the transfer currents were not measured at the maximum quench current of $4800 \mathrm{~A}$ needed for operation of the triplet quads at $1 \mathrm{TeV}$.

The upper of the two lines on each of the plots is the nominal (Pink Book) transfer constant value while the lower line is $0.1 \%$ less, to give a sense of the scale.

${ }^{7}$ I am indebted to Ray Hanft for suggesting this method of studying the variation.
} 
$\delta_{m}$ The contribution due to the finite precision of the measurements.

$\delta_{l}$ The uncertainty in the length of the individual quadrupoles.

$l$ The nominal length of the magnets.

If we take the corrected data at $4000 \mathrm{~A}$ for the 132 " and the 232" quadrupoles we can use the above equation, and the calculated variances to compute $\delta_{m}$ and $\delta_{l}$ with the following results:

$\delta_{m}=0.004 \%$

$\delta_{l}=0.1 \mathrm{in}$.

The contribution to the variance from the uncertainties in measuring the transfer constant $(0.004 \%)$ is less than the $0.05 \%$ found from repeated measurement of an individual magnet.

If we use these values to compute the expected fractional uncertainty of the 54" quadrupoles we find a value of $0.173 \%$ to be compared with the observed value of $0.176 \%$; very good agreement indeed! ${ }^{8}$

From the above discussion we would conclude that the observed variation in the measured transfer is due to the actual variation in the strength of the quadrupoles and not to precision of the measuring process. In that case the magnet to magnet variation of the 232 " quadrupoles is $\approx 0.05 \%$ and for the 132 " quadrupoles it is $\approx 0.07 \%$.

The nature of the low- $\beta$ is such that changes in the strengths of the low$\beta$ quadrupoles, especially the 232" quadrupoles, of the order of $0.05 \%$ can produce a large $(\approx 20-50 \%) \beta$ wave in the Tevatron. It is not obvious that we have not measured the transfer constants of the individual quadrupoles well enough to be used in a realistic lattice calculation for the Tevatron.

\footnotetext{
${ }^{8}$ If the MTF value for $\delta_{m}$ of $0.05 \%$ is used then the computed value for the variance for the $54^{n}$ magnets would be $0.180 \%$, still in good agreement.
} 
Table I- Quench Performance of the Low- $\beta$ Quadrupoles- 4.6K ${ }^{9}$

\begin{tabular}{|l|r|r|r|r|}
\hline Magnet & $\begin{array}{r}\text { Quench } \\
\text { (amps) }\end{array}$ & $\begin{array}{r}\text { Cycle } \\
\text { 75amps/s } \\
\text { (amps) }\end{array}$ & $\begin{array}{r}\text { Cycle } \\
\text { 200amps/s } \\
\text { (amps) }\end{array}$ & $\begin{array}{r}\text { Endurance } \\
\text { (amps) }\end{array}$ \\
\hline N1301F & 5214 & 5088 & 4224 & 4807 \\
N1303F & 5088 & & & 4600 \\
N1307F & 5273 & 5108 & 4632 & 4807 \\
N1309F & 5214 & 5127 & 4782 & 4850 \\
B1311F & 5255 & & & 4801 \\
B1313F & 5294 & & & 4818 \\
B1315F & 5229 & 5054 & 3856 & \\
B1317F & 5200 & 4938 & 4001 & \\
B1321F & 5171 & 4879 & 4467 & 4855 \\
\hline N2301F & 5137 & 4516 & & 4801 \\
N2303F & 4829 & 4650 & 4208 & 4701 \\
N2305F & 5205 & 5093 & 4404 & 4807 \\
N2307F & 5306 & 5185 & 3977 & 4807 \\
N2309F & 5243 & 5112 & 4729 & 4808 \\
\hline N5401F & 5098 & & 4268 & 5006 \\
N5403F & 4786 & 4724 & 3899 & 4705 \\
N5407F & 4831 & 4797 & -4375 & 4758 \\
N5409F & 5083 & 4947 & 3754 & 5015 \\
N5411F & 5302 & & & 4603 \\
N5413F & 5161 & & & 3001 \\
N5415F & 5164 & & & 4608 \\
N5417F & 5175 & & & 2997 \\
N5419F & 5171 & 5088 & 4719 & 4855 \\
N5421F & 5209 & & & 4307 \\
N5423F & 5234 & 5142 & & 4807 \\
\hline
\end{tabular}

\footnotetext{
${ }^{\circ}$ Blank spaces indicate that no data are available.
} 
Table II

Harmonics of the Low- $\beta$ Quadrupoles ${ }^{10}$

\begin{tabular}{|c|r|r|r|r|r|r|}
\hline $\begin{array}{c}\text { Nominal } \\
\text { Magnet } \\
\text { Length }\end{array}$ & \multicolumn{2}{|c|}{ 132" } & \multicolumn{2}{|c|}{} \\
\hline Harmonic & Average & Variance & \multicolumn{2}{|c|}{ Average } & Variance & \multicolumn{2}{|c|}{ Average } & Variance \\
\hline b02 & 0.61 & 1.53 & -0.55 & 1.95 & 0.62 & 1.03 \\
b03 & -0.44 & 1.01 & 0.02 & 0.89 & 0.21 & 0.40 \\
b04 & -0.22 & 0.32 & 0.28 & 0.23 & 0.29 & 0.50 \\
b05 & -2.42 & 1.08 & -2.01 & 0.85 & -3.10 & 1.44 \\
b06 & 0.03 & 0.36 & 0.01 & 0.17 & 0.05 & 0.26 \\
b07 & -0.04 & 0.18 & -0.06 & 0.19 & 0.05 & 0.11 \\
b08 & -0.03 & 0.19 & 0.04 & 0.12 & 0.08 & 0.19 \\
b09 & -0.90 & 0.20 & -0.68 & 0.11 & -0.75 & 0.17 \\
b10 & -0.04 & 0.23 & 0.06 & 0.10 & 0.03 & 0.14 \\
b11 & 0.03 & 0.25 & -0.01 & 0.06 & 0.01 & 0.25 \\
b12 & 0.14 & 0.25 & -0.08 & 0.16 & -0.12 & 0.51 \\
b13 & 1.30 & 0.21 & 1.36 & 0.24 & 1.21 & 0.17 \\
b14 & -0.08 & 0.15 & 0.02 & 0.13 & -0.02 & 0.60 \\
a02 & 0.30 & 2.59 & 0.12 & 3.17 & -0.63 & 2.65 \\
a03 & -0.47 & 0.98 & -0.50 & 0.86 & 0.13 & 0.95 \\
a04 & -0.49 & 0.42 & 0.35 & 0.66 & -0.31 & 0.68 \\
a05 & 0.08 & 0.42 & 0.10 & 0.24 & -0.03 & 0.59 \\
a06 & 0.17 & 0.26 & -0.08 & 0.39 & 0.01 & 0.29 \\
a07 & 0.06 & 0.21 & -0.07 & 0.14 & 0.02 & 0.15 \\
a08 & -0.04 & 0.20 & 0.08 & 0.11 & 0.05 & 0.13 \\
a09 & 0.16 & 0.20 & 0.14 & 0.20 & 0.17 & 0.10 \\
a10 & 0.06 & 0.25 & -0.04 & 0.09 & -0.07 & 0.19 \\
a11 & 0.07 & 0.19 & -0.12 & 0.11 & -0.07 & 0.21 \\
a12 & -0.04 & 0.21 & -0.11 & 0.17 & -0.19 & 0.38 \\
a13 & -0.58 & 0.26 & -0.26 & 0.20 & -0.22 & 0.87 \\
a14 & -0.21 & 0.12 & -0.23 & 0.19 & -0.29 & 0.14 \\
\hline & & & & & & \\
\hline
\end{tabular}

\footnotetext{
${ }^{10}$ The units of the $\mathrm{n}^{\text {th }}$ harmonic are $10^{-4} / \mathrm{in}^{n}$
} 
Table III

Magnet Length Used to Compute the Transfer Constants

\begin{tabular}{|c|c|}
\hline Nominal Magnet & Magnet Length \\
\hline $54^{\prime \prime}$ & $55.19 "$ \\
$132 "$ & $132 "$ \\
$232 "$ & $232 "$ \\
\hline
\end{tabular}

Table IVa

Average Transfer Constants as a Function of Current-132" Quadrupoles.

\begin{tabular}{|r|r|r|r|r|}
\hline & \multicolumn{2}{|c|}{ Uncorrected } & \multicolumn{2}{c|}{ Corrected } \\
Current & Average & Variance & Average & Variance \\
\hline$(\mathrm{A})$ & $(\mathrm{T} / \mathrm{cm} / \mathrm{kA})$ & $(\mathrm{T} / \mathrm{cm} / \mathrm{kA})$ & $(\mathrm{T} / \mathrm{cm} / \mathrm{kA})$ & $(\mathrm{T} / \mathrm{cm} / \mathrm{kA})$ \\
\hline 500.0 & 0.28908 & 0.00031 & 0.28943 & 0.00021 \\
660.0 & 0.28946 & 0.00032 & 0.28967 & 0.00023 \\
1000.0 & 0.28986 & 0.00027 & 0.28988 & 0.00021 \\
1500.0 & 0.29013 & 0.00029 & 0.28998 & 0.00021 \\
2000.0 & 0.29033 & 0.00030 & 0.29000 & 0.00023 \\
2500.0 & 0.29051 & 0.00033 & 0.28999 & 0.00021 \\
3000.0 & 0.29068 & 0.00031 & 0.28994 & 0.00021 \\
3500.0 & 0.29083 & 0.00036 & 0.28984 & 0.00024 \\
4000.0 & 0.29091 & 0.00037 & 0.28963 & 0.00021 \\
4500.0 & 0.29080 & 0.00042 & 0.28920 & 0.00017 \\
\hline
\end{tabular}


Table IVb

Average Transfer Constants as a Function of Current-232" Quadrupoles.

\begin{tabular}{|r|r|r|r|r|}
\hline & \multicolumn{2}{|c|}{ Uncorrected } & \multicolumn{2}{c|}{ Corrected } \\
Current & Average & Variance & Average & Variance \\
\hline$(\mathrm{A})$ & $(\mathrm{T} / \mathrm{cm} / \mathrm{kA})$ & $(\mathrm{T} / \mathrm{cm} / \mathrm{kA})$ & $(\mathrm{T} / \mathrm{cm} / \mathrm{kA})$ & $(\mathrm{T} / \mathrm{cm} / \mathrm{kA})$ \\
\hline 500.0 & 0.28937 & 0.00031 & 0.28973 & 0.00009 \\
660.0 & 0.28978 & 0.00035 & 0.28998 & 0.00009 \\
1000.0 & 0.29023 & 0.00033 & 0.29020 & 0.00017 \\
1500.0 & 0.29062 & 0.00033 & 0.29031 & 0.00009 \\
2000.0 & 0.29096 & 0.00036 & 0.29033 & 0.00009 \\
2500.0 & 0.29132 & 0.00036 & 0.29032 & 0.00012 \\
3000.0 & 0.29171 & 0.00037 & 0.29027 & 0.00015 \\
3500.0 & 0.29212 & 0.00038 & 0.29017 & 0.00015 \\
4000.0 & 0.29249 & 0.00044 & 0.28996 & 0.00012 \\
4500.0 & 0.29271 & 0.00050 & 0.28952 & 0.00015 \\
\hline
\end{tabular}

Table IVc

Average Transfer Constants as a Function of Current-54"

Quadrupoles.

\begin{tabular}{|r|r|r|}
\hline & \multicolumn{2}{|c|}{ Uncorrected } \\
Current & Average & Variance \\
\hline$(\mathrm{A})$ & $(\mathrm{T} / \mathrm{cm} / \mathrm{kA})$ & $(\mathrm{T} / \mathrm{cm} / \mathrm{kA})$ \\
\hline 500.0 & 0.28857 & 0.00044 \\
660.0 & 0.28895 & 0.00046 \\
1000.0 & 0.28934 & 0.00048 \\
1500.0 & 0.28957 & 0.00052 \\
2000.0 & 0.28969 & 0.00050 \\
2500.0 & 0.28976 & 0.00048 \\
3000.0 & 0.28979 & 0.00049 \\
3500.0 & 0.28979 & 0.00051 \\
4000.0 & 0.28970 & 0.00051 \\
4500.0 & 0.28941 & 0.00049 \\
\hline
\end{tabular}


Table V

Comparison of the Average Corrected Transfer Constant as a Function of Current

\begin{tabular}{|r|r|r|r|r|r|r|}
\hline & \multicolumn{2}{|c|}{$132^{\prime \prime}$ Quads } & \multicolumn{2}{|c|}{$232^{\prime \prime}$ Quads } & & \\
\hline & $\begin{array}{r}\text { Transfer } \\
\text { Constant }\end{array}$ & $\begin{array}{r}\text { Transfer } \\
\text { Variance }\end{array}$ & $\begin{array}{r}1000^{*} \\
\text { Constant } \\
\text { Variance }\end{array}$ & $\begin{array}{r}1000^{*} \\
\text { Diff. }\end{array}$ & Error \\
\hline $\mathrm{kA}$ & $\mathrm{T} / \mathrm{cm} / \mathrm{kA}$ & $\mathrm{T} / \mathrm{cm} / \mathrm{kA}$ & $\mathrm{T} / \mathrm{cm} / \mathrm{kA}$ & $\mathrm{T} / \mathrm{cm} / \mathrm{kA}$ & & \\
\hline 500 & 0.28943 & 0.00021 & 0.28973 & 0.00009 & -0.30 & 0.23 \\
660 & 0.28967 & 0.00023 & 0.28998 & 0.00009 & -0.31 & 0.25 \\
1000 & 0.28988 & 0.00021 & 0.29020 & 0.00017 & -0.32 & 0.27 \\
1500 & 0.28998 & 0.00021 & 0.29031 & 0.00009 & -0.33 & 0.23 \\
2000 & 0.29000 & 0.00023 & 0.29033 & 0.00009 & -0.33 & 0.25 \\
2500 & 0.28999 & 0.00021 & 0.29032 & 0.00012 & -0.33 & 0.24 \\
3000 & 0.28994 & 0.00021 & 0.29027 & 0.00015 & -0.33 & 0.26 \\
3500 & 0.28984 & 0.00024 & 0.29017 & 0.00015 & -0.33 & 0.28 \\
4000 & 0.28963 & 0.00021 & 0.28996 & 0.00012 & -0.33 & 0.24 \\
4500 & 0.28920 & 0.00017 & 0.28952 & 0.00015 & -0.32 & 0.23 \\
\hline
\end{tabular}




\section{Strong Correctors}

In order to match the lattice functions in the low- $\beta$ insertions with the lattice functions normally found in the lattice at the end of the insertions, high gradient correctors are used. There are two types of high gradient correctors. The first is a two shell cold iron quadrupole (the same as was used for the construction of the long low- $\beta$ quadrupoles and referred to as a "717" cross section) coupled to a spool correction package. The other kind of high gradient correcior is a 7.5" O.D. one shell quadrupole (referred to as a "S5" cross section) which replaces one of the correction coil packages in a standard spool. ${ }^{2}$

The four high gradient correctors on each side of the low- $\beta$ insertion are packaged with the normal correction coils and thus appear in different packages. Table VI gives the name of the different packages (or devices) and their composition.

Table VI. Low- $\beta$ Insertion- Special Spool Package Composition

\begin{tabular}{|c|c|c|c|}
\hline $\begin{array}{c}\text { Device } \\
\text { Name }\end{array}$ & $\begin{array}{c}\text { Upstream } \\
\text { Cross Section }\end{array}$ & $\begin{array}{c}\text { Downstream } \\
\text { Cross Section }\end{array}$ & $\begin{array}{c}\text { Lattice } \\
\text { Function }\end{array}$ \\
\hline TSJ & "717" & DSQI & T6 \\
TSK & "717" & DSQII & T6 \\
TSL & DD & & Q5 Spool. \\
TSM & "S5" & DSQI & T7,T8,T9 \\
TSN & "S5" & DSQII & T7,T8,T9 \\
TSP & DDQ & & Q1 Spool. \\
\hline
\end{tabular}

The high gradient quadrupoles were measured at MTF in the same way as the other low- $\beta$ quadrupoles except that no reliable quench currents are available.

\section{Harmonics}

The magnetic field for these quadrupoles was measured using the same technique as was used for the low- $\beta$ quadrupoles and the harmonic coefficients were extracted at different currents and when the current was increasing and when it was decreasing. Figure $5^{11}$ is a plot of the average and the variance

\footnotetext{
${ }^{11}$ The $b_{s}$ moment for the TSM and TSN quadrupoles is off the scale of the figure.
} 
harmonics, at the maximum current at which they were measured, for the different multipole coefficients and for the different types of spools. The averages of $b_{n}$ and $a_{n}$ are, except for the allowed $b_{5}, b_{9}$, and $b_{13}$ moments, small and are less than $10^{-4} / \mathrm{in}^{n}$. It should be noted that the measurements of the values of the harmonics for the strong correctors are affected by any fields in the weak corrector. ${ }^{12}$ This problem was not recognized at the time the measurements were made. A procedure has been developed to extract the true geometric coefficients but it has not been applied to the data harmonics presented which here are those calculated by MTF. The data are summarized in Table VII.

\section{Transfer Constants}

The transfer constant is again calculated from the measured $\int B^{\prime} d l$, for a given current, and by dividing by the length of the magnet and the value of the current at which the measurement was made. Table VIII gives the values of the magnet lengths used to compute the transfer constants for the strong correctors. The values of the measured transfer constants are given in Table IX and plotted in figure 6.

The TSJ and TSK spools differ from ea th other only in the corrector package and have the same high gradient coil configuration as the low- $\beta$ quadrupoles discussed above. If we use the numbers for $\delta_{m}$ and $\delta_{l}$ found previously to compute the expected variance in the measurements of the transfer constants for these coils we find, combining the data from the TSJ and the TSK magnets, agreement with the observed variance. Thus though spool TSK-4 has a measured transfer constant significantly lower than that of the other "717" spools it is not outside the expected values due to fabrication tolerances.

There is no apparent difference in strength between the TSM and TSN spools.

\footnotetext{
${ }^{12}$ R. Hanft private communication.
} 
Table VIIa- Harmonics of the High Gradient Spools ${ }^{9}$

\begin{tabular}{|c|r|r|r|r|}
\hline Spool Type & \multicolumn{2}{|c|}{ TSJ } & \multicolumn{2}{c|}{ TSK } \\
\hline Harmonic & Average & Variance & Average & Variance \\
\hline b02 & 1.70 & 2.47 & 1.43 & 3.09 \\
b03 & -0.32 & 0.79 & -0.08 & 0.67 \\
b04 & 0.12 & 0.29 & 0.25 & 0.62 \\
b05 & -5.44 & 0.47 & -5.58 & 0.54 \\
b06 & -0.02 & 0.06 & 0.11 & 0.25 \\
b07 & 0.07 & 0.05 & -0.01 & 0.31 \\
b08 & 0.15 & 0.09 & -0.09 & 0.09 \\
b09 & -1.42 & 0.30 & -1.10 & 0.21 \\
b10 & 0.04 & 0.12 & -0.13 & 0.94 \\
b11 & 0.09 & 0.09 & -0.69 & 0.65 \\
b12 & -0.05 & 0.04 & 0.46 & 2.80 \\
b13 & 0.65 & 0.07 & 2.85 & 1.51 \\
b14 & -0.11 & 0.06 & -0.21 & 0.88 \\
a02 & -0.87 & 5.60 & -2.65 & 2.06 \\
a03 & -0.36 & 1.00 & -0.78 & 0.71 \\
a04 & -0.12 & 0.36 & -0.55 & 0.57 \\
a05 & 0.51 & 0.54 & -0.47 & 1.06 \\
a06 & 0.31 & 0.60 & 0.31 & 0.31 \\
a07 & 0.08 & 0.09 & -0.06 & 0.20 \\
a08 & 0.01 & 0.07 & -0.02 & 0.27 \\
a09 & 0.44 & 0.08 & 0.46 & 0.26 \\
a10 & 0.09 & 0.16 & -0.09 & 0.50 \\
a11 & -0.08 & 0.08 & 0.19 & 1.95 \\
a12 & -0.11 & 0.15 & 1.40 & 1.38 \\
a13 & -0.44 & 0.05 & -0.91 & 2.28 \\
a14 & 0.01 & 0.20 & -1.15 & 0.90 \\
\hline
\end{tabular}


Table VIIb- Harmonics of the High Gradient Spools ${ }^{\circ}$

\begin{tabular}{|c|r|r|r|r|}
\hline Spool Type & \multicolumn{2}{|c|}{ TSM } & \multicolumn{2}{|c|}{ TSN } \\
\hline Harmonic & Average & Variance & Average & Variance \\
\hline b02 & -2.85 & 6.89 & -2.22 & 3.35 \\
b03 & -0.11 & 0.85 & 0.07 & 1.09 \\
b04 & 0.06 & 1.75 & 1.16 & 1.60 \\
b05 & -16.43 & 1.45 & -16.25 & 0.72 \\
b06 & 0.45 & 0.26 & 0.60 & 0.44 \\
b07 & -0.06 & 0.17 & -0.01 & 0.35 \\
b08 & -0.28 & 0.14 & -0.01 & 0.15 \\
b09 & -1.07 & 0.31 & -1.03 & 0.14 \\
b10 & 0.08 & 0.18 & 0.16 & 0.15 \\
b11 & 0.17 & 0.19 & 0.22 & 0.30 \\
b12 & 0.00 & 0.22 & -0.07 & 0.18 \\
b13 & 0.21 & 0.14 & 0.05 & 0.47 \\
b14 & 0.03 & 0.20 & 0.01 & 0.34 \\
a02 & 1.17 & 3.93 & -0.05 & 3.33 \\
a03 & 0.71 & 2.62 & -1.35 & 3.45 \\
a04 & -0.17 & 1.50 & 0.18 & 1.74 \\
a05 & 0.39 & 0.82 & 0.66 & 1.02 \\
a06 & 1.05 & 0.56 & 1.07 & 0.43 \\
a07 & 0.23 & 0.50 & 0.44 & 0.44 \\
a08 & 0.09 & 0.22 & 0.07 & 0.20 \\
a09 & 0.69 & 0.20 & 0.67 & 0.22 \\
a10 & 0.09 & 0.20 & 0.14 & 0.19 \\
a11 & -0.02 & 0.18 & -0.09 & 0.13 \\
a12 & -0.16 & 0.17 & -0.27 & 0.46 \\
a13 & -0.21 & 0.20 & -0.33 & 0.30 \\
a14 & -0.03 & 0.18 & 0.00 & 0.17 \\
\hline & & & & \\
\hline
\end{tabular}


Table VIII

Magnet Length Used to Compute the Transfer Constants ${ }^{2}$

\begin{tabular}{|c|c|}
\hline Spool Type & Magnet Length \\
\hline TSJ,TSK & $23.875^{\prime \prime}$ \\
TSM,TSN & $25.0^{\prime \prime}$ \\
\hline
\end{tabular}

Table IXa

Average Transfer Constants as a Function of Current.

\begin{tabular}{|r|r|r|r|r|}
\hline Spool Type & \multicolumn{2}{|c|}{ TSJ } & \multicolumn{2}{c|}{ TSK } \\
\hline Current & Average & Variance & Average & Variance \\
\hline$(\mathrm{A})$ & $(\mathrm{T} / \mathrm{cm} / \mathrm{kA})$ & $(\mathrm{T} / \mathrm{cm} / \mathrm{kA})$ & $(\mathrm{T} / \mathrm{cm} / \mathrm{kA})$ & $(\mathrm{T} / \mathrm{cm} / \mathrm{kA})$ \\
\hline 500.0 & 0.28722 & 0.00012 & 0.28718 & 0.00141 \\
660.0 & 0.28765 & 0.00009 & 0.28759 & 0.00141 \\
1000.0 & 0.28808 & 0.00019 & 0.28799 & 0.00139 \\
1500.0 & 0.28831 & 0.00023 & 0.28820 & 0.00141 \\
2000.0 & 0.28841 & 0.00017 & 0.28828 & 0.00142 \\
2500.0 & 0.28845 & 0.00023 & 0.28829 & 0.00144 \\
3000.0 & 0.28844 & 0.00021 & 0.28825 & 0.00146 \\
3500.0 & 0.28837 & 0.00024 & 0.28815 & 0.00150 \\
4000.0 & 0.28820 & 0.00024 & 0.28794 & 0.00153 \\
4300.0 & 0.28800 & 0.00023 & 0.28776 & 0.00158 \\
\hline
\end{tabular}

Table IXb

Average Transfer Constants as a Function of Current.

\begin{tabular}{|r|r|r|r|r|}
\hline Spool Type & \multicolumn{2}{|c|}{ TSM } & \multicolumn{2}{c|}{ TSN } \\
\hline Current & Average & Variance & Average & Variance \\
\hline$(\mathrm{A})$ & $(\mathrm{T} / \mathrm{cm} / \mathrm{kA})$ & $(\mathrm{T} / \mathrm{cm} / \mathrm{kA})$ & $(\mathrm{T} / \mathrm{cm} / \mathrm{kA})$ & $(\mathrm{T} / \mathrm{cm} / \mathrm{kA})$ \\
\hline 100.0 & 0.55351 & 0.00120 & 0.55370 & 0.00123 \\
200.0 & 0.55690 & 0.00134 & 0.55706 & 0.00106 \\
300.0 & 0.55904 & 0.00137 & 0.55920 & 0.00105 \\
400.0 & 0.56019 & 0.00139 & 0.56035 & 0.00104 \\
500.0 & 0.56082 & 0.00140 & 0.56098 & 0.00106 \\
600.0 & 0.56121 & 0.00143 & 0.56135 & 0.00104 \\
700.0 & 0.56141 & 0.00142 & 0.56156 & 0.00105 \\
800.0 & 0.56145 & 0.00142 & 0.56160 & 0.00106 \\
900.0 & 0.56130 & 0.00140 & 0.56145 & 0.00104 \\
1000.0 & 0.56090 & 0.00142 & 0.56105 & 0.00101 \\
\hline
\end{tabular}



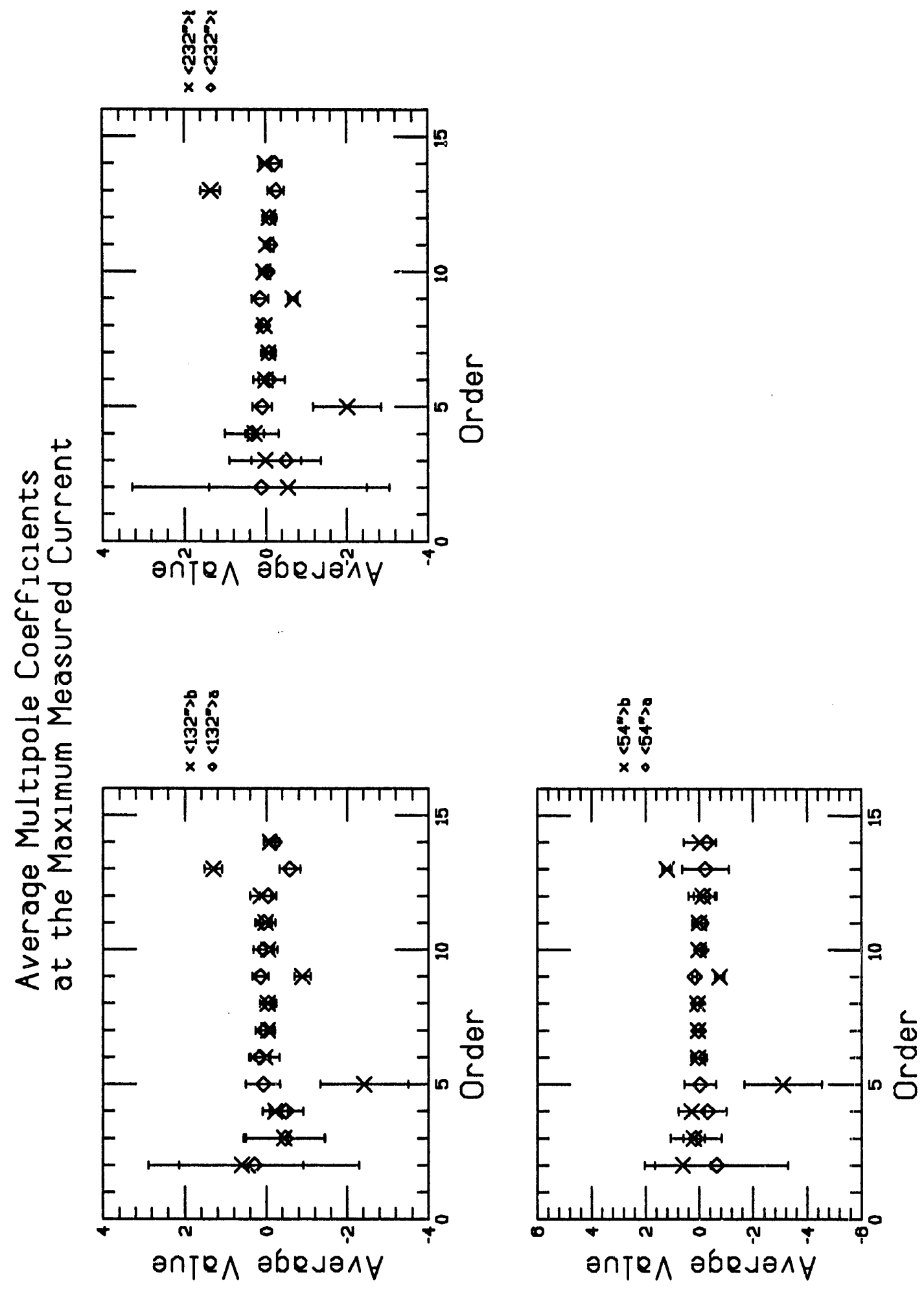

离 

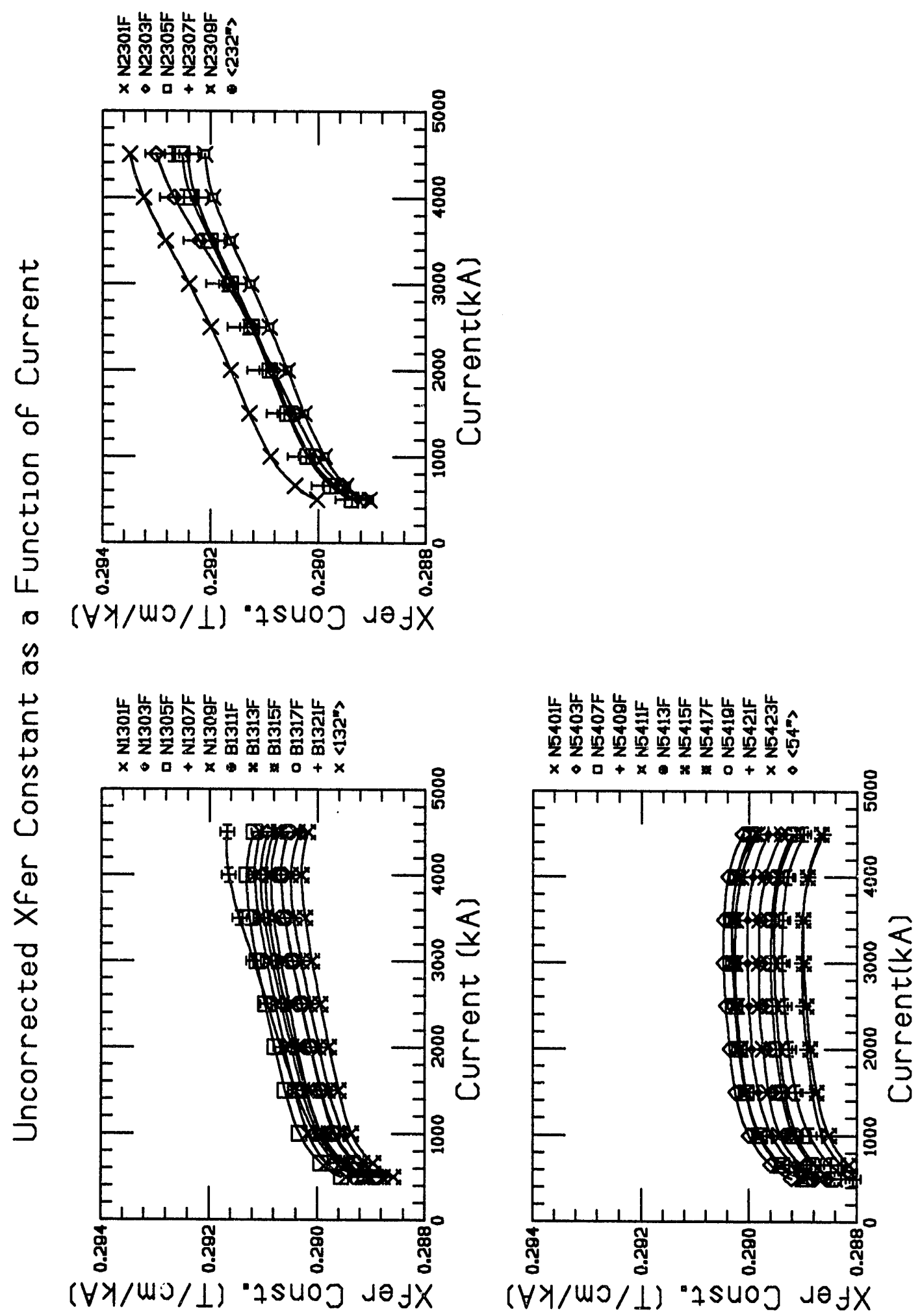

$N$
0
5
$\stackrel{5}{0}$
4 

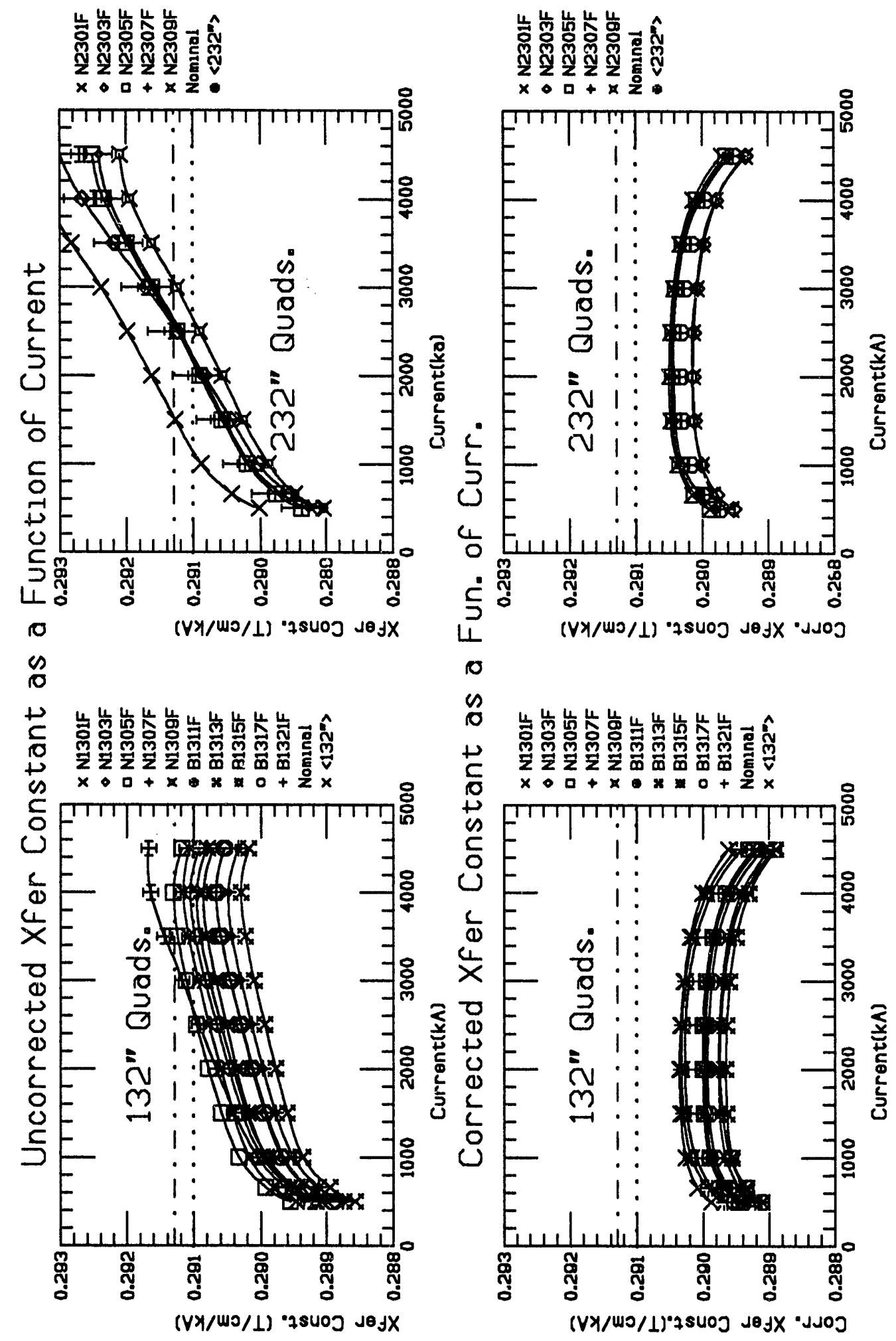

$m$
0
$\stackrel{0}{5}$
$\stackrel{5}{6}$ 


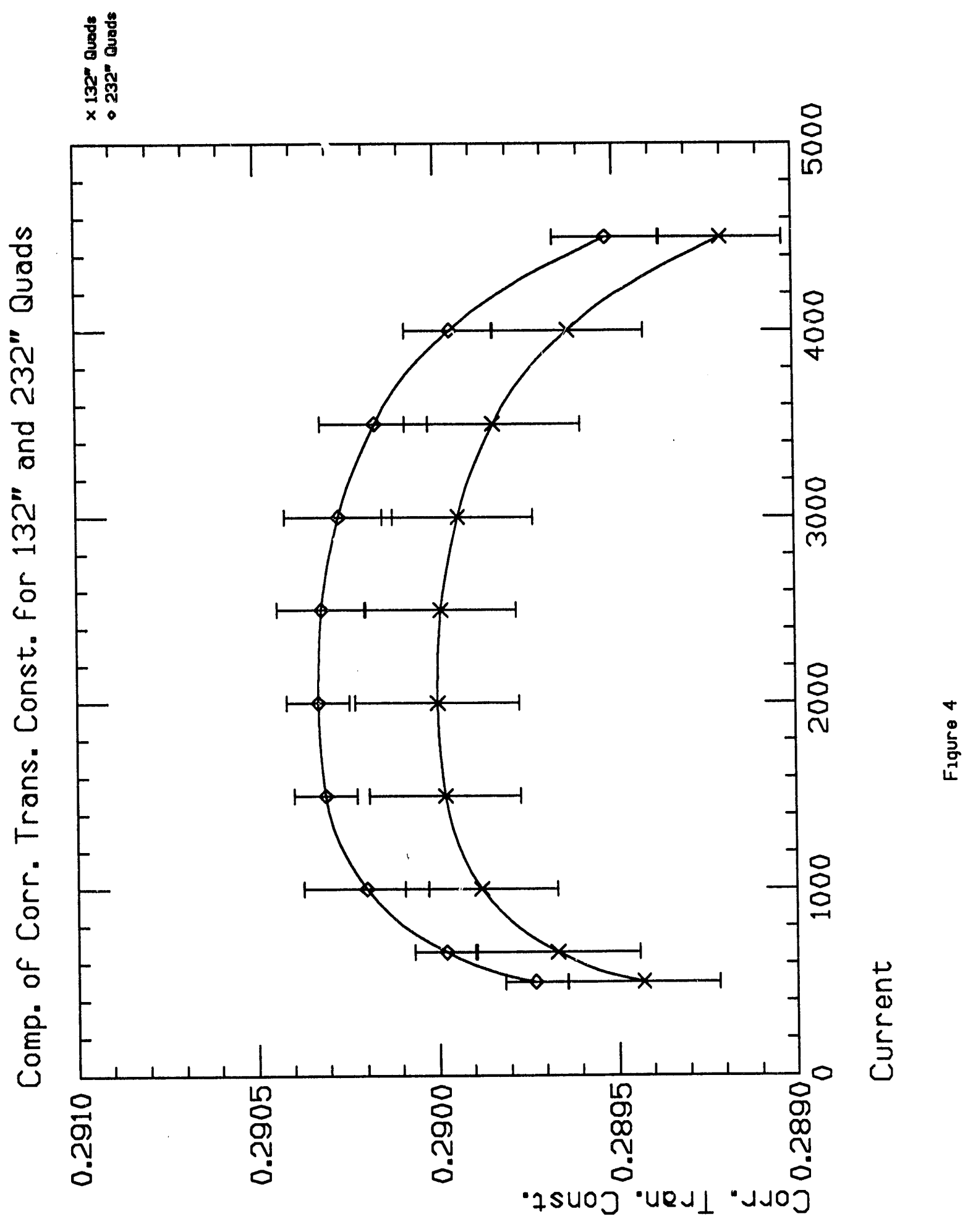

19 

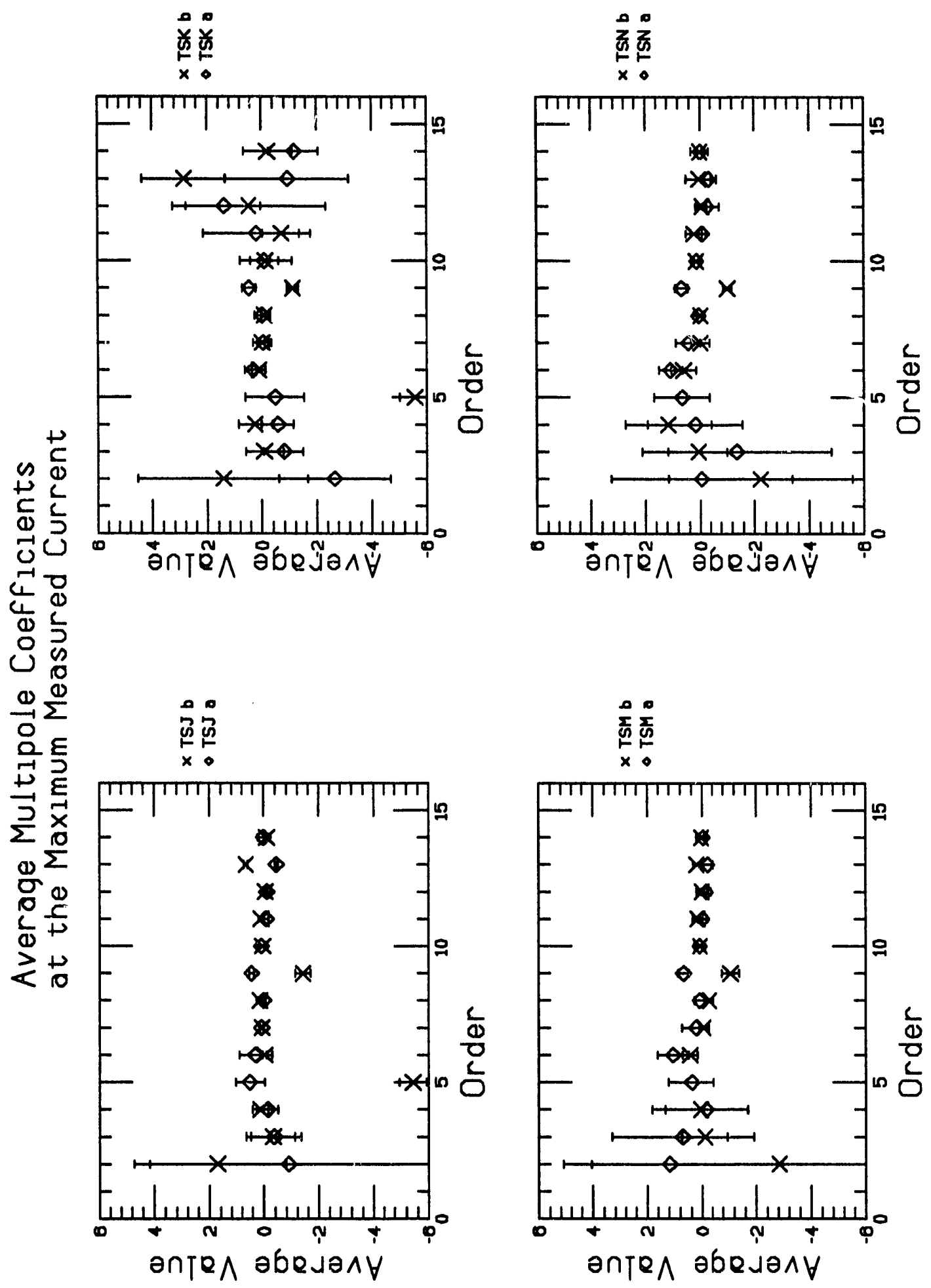

10
0
5
5
4
4 

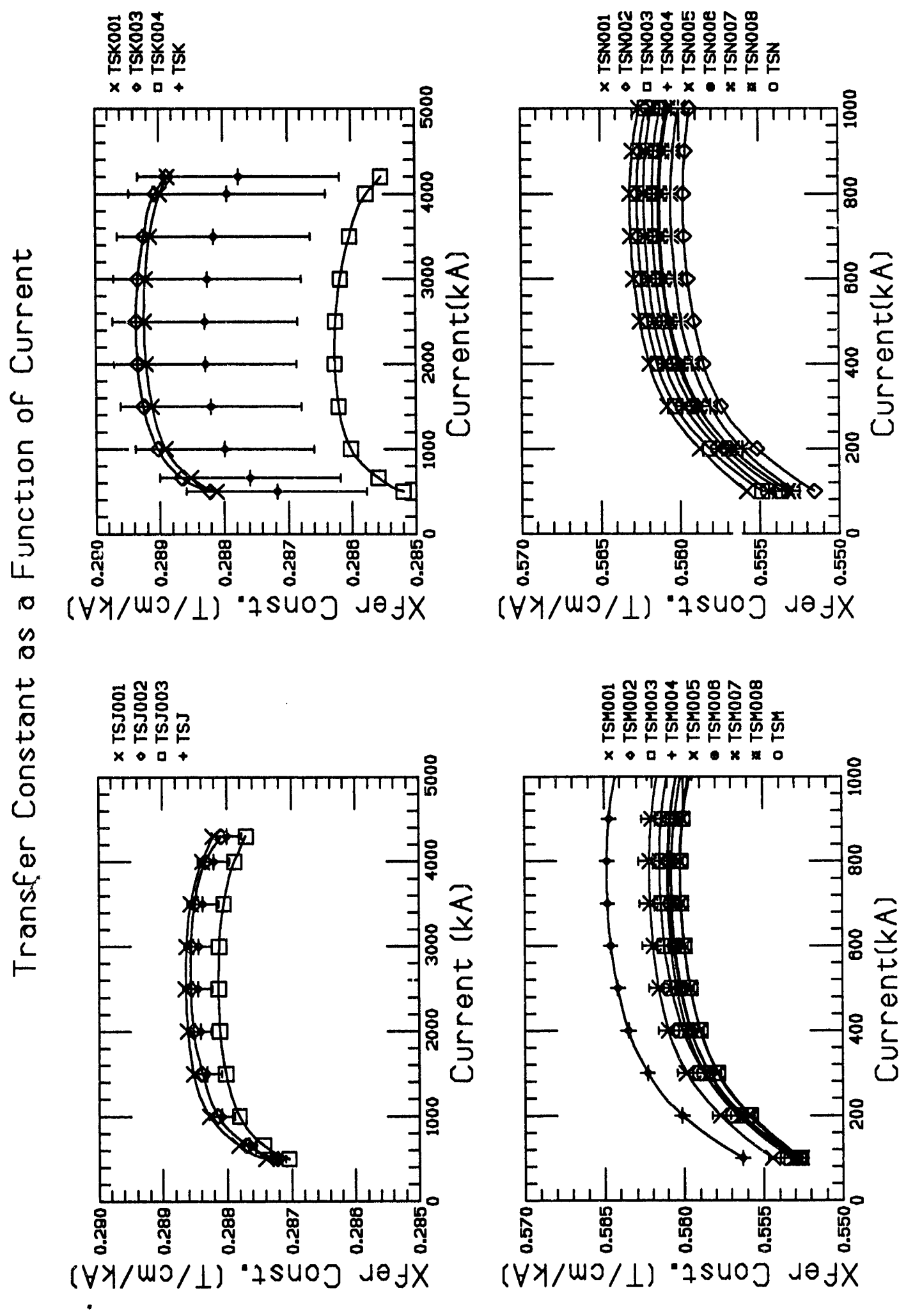

-

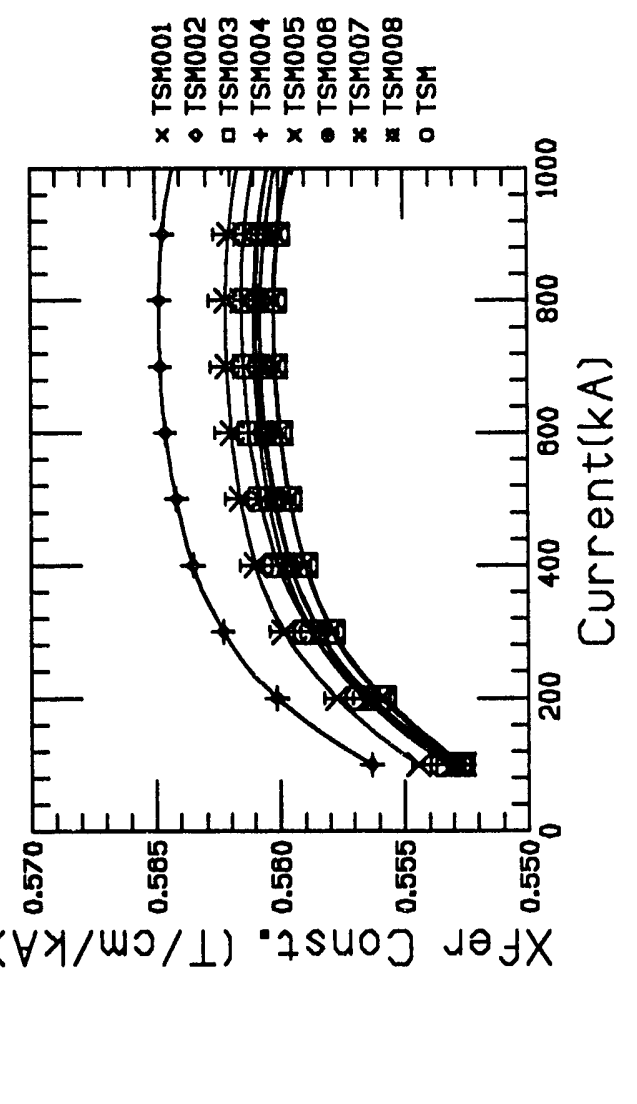

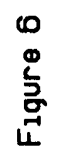


